Coordenadoria de Controle de Doenças, Secretaria de Estado da Saúde de São Paulo
Correspondência | Correspondence: Secretaria de Estado da Saúde de São Paulo Av. Dr. Arnaldo, 351, $1^{\circ}$ andar, sala 135 01246-901 São Paulo, SP, Brasil

E-mail: bepa@saude.sp.gov.br

Texto de difusão técnico-científica da Secretaria de Estado da Saúde de São Paulo

\section{Curso de formação de oficiais de controle animal: nova perspectiva nos serviços de controle de zoonoses do Estado de São Paulo}

\section{Upgrading course for animal control agents: a new perspective on the zoonosis control services in the State of São Paulo, Southeastern Brazil}

Com a domesticação dos animais, o ser humano tornouse responsável por prover suas necessidades, controlar suas populações, zelar por sua saúde e bem-estar. Cães e gatos são as espécies domesticadas mais utilizadas para preencher necessidades afetivas dos seres humanos, característica que contribui para a melhoria da saúde mental e interações sociais, facilitando a integração da comunidade. Contudo, atrelados a essa relação estão o manejo inadequado e a falta de controle das populações de cães e gatos, representando um risco para a saúde humana, ambiental e dos próprios animais.

Estima-se que a população canina mundial seja de 500 milhões de indivíduos. De acordo com a Organização Mundial da Saúde, a apreensão sistemática e a eliminação de cães foram utilizadas em várias partes do mundo como método de controle, embora estudos atuais mostrem que a eutanásia é menos efetiva e apresenta maior custo em relação ao controle da reprodução animal e educação da comunidade. Os métodos tradicionais de controle populacional de cães e gatos também têm impactos negativos sobre a sociedade que critica a ação dos funcionários que desempenham a função de "laçadores", geralmente identificados como "vilões assassinos". Deficiências no manejo e no trato dos animais tornam o órgão público e seus funcionários desrespeitados pela comunidade.

Em 2005, visando a humanização dos serviços de controle de populações animais e de zoonoses, o governo do Estado de São Paulo, por meio da Coordenadoria de Controle de Doenças da Secretaria de Estado da Saúde (CCD/SES-SP), implantou o Curso de Formação de Oficiais de Controle Animal (Foca). Parceria entre o poder público estadual e as organizações nãogovernamentais (ONG) de proteção animal, o Instituto
Técnico de Educação e Controle Animal (Itec) e a World Society for the Protection of Animals (WSPA), o Foca é voltado para médicos-veterinários, gestores dos serviços de controle de zoonoses e funcionários que realizam o manejo de cães e gatos, atuando no recolhimento (captura) e nas atividades de manutenção em canis ou gatis.

A ênfase do curso é a capacitação dos funcionários para a implantação de ações efetivas de controle populacional de cães e gatos, de acordo com preceitos técnicos e éticos, com foco no manejo etológico, ou seja, o manejo racional e sem violência que considera o comportamento natural da espécie-alvo e promove seu bem-estar.

\section{CARACTERÍSTICAS DO CURSO FOCA}

O curso Foca utiliza metodologia de ensino baseada em três domínios de aprendizagem: o cognitivo, o motor e o afetivo. Ao mesmo tempo em que gera conhecimento e desenvolve habilidades necessárias à profissão, o método trabalha com valores, atitudes e posturas que fazem o participante reconhecer-se como ser humano construtor da saúde e da paz. O curso valoriza a mudança de imagem desses profissionais, substituindo o antigo "laçador" por um oficial de controle animal, promotor da saúde, educador e aliado da comunidade.

Com duração de uma semana e carga horária de 44 horas, o Foca é composto por aulas teóricas e práticas, realizadas nas ruas, em canis e gatis vinculados aos serviços de controle animal e com a comunidade. Além disso, o curso promove atividades em grupo e individuais, utilizando-se de algumas dinâmicas de sensibilização em que os participantes são avaliados por meio de provas teórica e prática. 
O Foca é executado por uma equipe multiprofissional que inclui, além de representantes do serviço público estadual e das ONGs de proteção animal, também os das prefeituras paulistas, com destaque para a da Capital paulista, Guarulhos, Jundiaí, Votorantim, Botucatu e Mogi das Cruzes, e de Camaragibe, em Pernambuco. Conta, ainda, com consultoria internacional de médicoveterinário especialista em comportamento animal da Universidad de Salle, Colômbia, e apoio do Conselho Regional de Medicina Veterinária do Estado de São Paulo. Em cada curso são envolvidos a prefeiturasede do evento e seu serviço municipal de controle de zoonoses ou animal.

Antes de iniciar o curso, a equipe responsável pela execução visita todos os Centros de Controle de Zoonoses ou canis e gatis dos municípios participantes para avaliação das condições de trabalho e manutenção dos animais. Aspectos epidemiológicos regionais também são avaliados. O conjunto dessas informações apóia o planejamento e organização do Foca, que é adequado à realidade de cada região.

No início do curso, os principais problemas identificados pelos participantes em sua rotina de trabalho são expostos no chamado "muro das lamentações". É construído, também, o "sonho coletivo" em relação ao trabalho que os oficiais desenvolvem ("árvore da esperança"). Ao longo do curso, essas informações são utilizadas pelos instrutores e palestrantes convidados.

O conteúdo teórico, apresentado durante a semana e cujo foco central é a humanização dos serviços, é dividido em três blocos. No primeiro, discute-se o controle populacional de cães e gatos, o que inclui o controle e prevenção das principais zoonoses e demais riscos que representam aos seres humanos, a outros animais e ao meio ambiente. No segundo bloco, são abordados o comportamento e bem-estar animais, com foco nos aspectos de manejo etológico. Saúde do trabalhador, princípios do Sistema Único de Saúde, e legislação são os temas do terceiro bloco. As práticas são realizadas levando-se em consideração a experiência dos participantes, suas habilidades e condições físicas. No decorrer do Foca são apresentadas técnicas e equipamentos para a melhoria do manejo.

O domínio afetivo é desenvolvido desde o início do curso em forma de dinâmicas, compartilhamentos, vivências e comprometimentos, sendo trabalhados os seguintes aspectos: o medo do novo (mudanças) e as resistências; a união e o contato físico entre os participantes; e o resgate da auto-estima, identificação/ reconhecimento de seus valores como ser humano.

\section{RESULTADOS DA ATUAÇÃO DO FOCA}

Realizados no estado de São Paulo desde sua criação em 2005, os cursos Foca já capacitaram 572 funcionários de 128 municípios, além de 13 participantes de sete Estados e um de Londres, Inglaterra.

Em junho de 2007, a CCD/SES-SP realizou o primeiro levantamento com os participantes de alguma edição do Foca para avaliar as mudanças ocorridas nos serviços municipais de controle de zoonoses e de controle animal após o curso. A avaliação foi feita por meio de questionários enviados eletronicamente. Os resultados referem-se à amostra de 31 municípios que responderam até o dia 12 daquele mês.

Chama atenção o fato de $100 \%$ dos locais que têm estrutura física de controle de zoonoses terem mudado imediatamente ou em curto prazo o manejo em alguma das atividades desenvolvidas diretamente com os animais, enquanto $34,4 \%$ implantaram atividades para o controle da reprodução. Dos municípios com programas de adoção de cães e gatos, $45 \%$ passaram a disponibilizar apenas animais esterilizados cirurgicamente. Dos que não faziam recolhimento seletivo, $47 \%$ passaram a fazê-lo e $21 \%$ iniciaram o atendimento clínico no serviço municipal. Cerca de $27 \%$ dos municípios já realizaram melhorias da estrutura física e no transporte de animais.

Em abril de 2008, durante o $13^{\circ}$ Foca, realizado em Dracena, no interior paulista, os municípios participantes elaboraram um documento referendando o curso como instrumento de humanização dos atuais e novos centros de controle de zoonoses. No documento intitulado "Carta de Dracena", os cursados relatam que o Foca permitiu discutir estratégias efetivas de controle da população de cães e gatos de rua e a viabilidade de implantação de um novo modelo de atendimento a esses animais. Os autores descrevem, ainda, que o processo promove uma transformação interna que se reflete em mudanças para toda a sociedade: "Ser um oficial de controle animal é ser um profissional preocupado com os animais humanos e não humanos."

Visando à disseminação dos conceitos preconizados pelo Foca, no mesmo ano, a CCD/SES-SP realizou o I Encontro Nacional de Oficiais de Controle Animal e o II Fórum de Controle Populacional de Cães e Gatos do Estado de São Paulo, reunindo 250 profissionais de municípios de todo o Brasil para discutir o tema. Durante os dois eventos, foram apresentados 30 trabalhos relatando as experiências práticas e exitosas no controle populacional e manejo etológico de cães e gatos adotadas pelos serviços municipais, sob a perspectiva do Foca.

Em 2009, o projeto Foca participou da quinta edição do Prêmio Governador Mario Covas, uma iniciativa do governo paulista, executado pela Secretaria de Estado de Gestão Pública e Fundação do Desenvolvimento Administrativo (Fundap), em parceria com a Fundação Mario Covas. A premiação tem o objetivo de identificar 
e valorizar as boas práticas de gestão pública por meio da busca contínua da modernização administrativa dos órgãos estaduais, com foco permanente no atendimento às demandas da população do Estado. De 184 trabalhos inscritos nas categorias de Excelência e Inovação em Gestão Pública, o projeto Foca foi selecionado entre os 25 melhores, recebendo menção honrosa na categoria Inovação em Gestão Pública.

Esses resultados mostram que a experiência do curso de formação de oficiais de controle animal, por meio de ações comprometidas com a humanização dos serviços de controle de zoonoses, possibilita incorporar conceitos de saúde animal no âmbito da saúde pública, assegurando ao mesmo tempo a saúde e a segurança da população, a preservação ambiental e o bem-estar de cães e gatos.

É nesse sentido que caminha o curso Foca, implantado pioneiramente no estado de São Paulo, em consonância com o Programa Nacional de Humanização dos Serviços de Saúde do Ministério da Saúde. Diferentemente do laçador, o oficial de controle animal adquire habilidades e competências para avaliar o comportamento desses animais, realizar o manejo etológico para a espécie-alvo e atuar como educador comunitário. 